\title{
The Effect of Different Absorber Configurations On The Exergy and The Energy of Parabolic Solar Dish
}

\author{
A'laa Taghi Al-Azawi ${ }^{1}$, Ali A. F. Al Hamadani ${ }^{2}$ \\ ${ }^{1}$ Department of mechanical engineering, postgraduate student (MSc.), College of engineering, Wasit University \\ E mail: alaataghi205@gmail.com \\ ${ }^{2}$ Asst. Prof., Department of mechanical, College of engineering, Wasit University \\ E mail: aalhamadani@uowasit.edu.iq
}

\begin{abstract}
The solar energy is the most important type of energy. The parabolic dish solar collector (PDSC) is the best type among other solar collectors because it is always tracking the sun movement. The exergy and the energy performances of a PDS were analyzed experimentally and numerically. The effect of different coil geometries and different mass flow rates of heat transfer fluid (HTF) were investigated. The PDS has parabolic dish and receiver with diameter (1.5) $\mathrm{m}$ and (0.2) $\mathrm{m}$ respectively. Concentration ratio is 56.25. The parabolic polar dish was supported by a tracking system with two axes. The types of the copper absorber were used which are: (spiral -helical) coil (SHC) and spiral-conical coil (SCC). The results showed that the useful energy and thermal efficiency are varying with solar radiation variation. The useful energy varying between (480-765) W for (SHC), the thermal efficiency varying between $(35.2-39.8) \%$ for (SHC). Exergy efficiency varying between $(6.9-8.6) \%$. It was shown that the higher values of useful energy for (spiral - helical) absorber was $0.1 \mathrm{~L} / \mathrm{min}$ flow rate.
\end{abstract}

Keywords-Parabolic dish collector; exergy efficiency; spiral-helical coil (SHC); spiral-conical coil (SCC)

\section{INTRODUCTION}

Huge energy sources such as (oil, fossil fuels) have been consumed due human being life progress all different areas of life and development. Moreover, the industrial's waste and environmental pollution resulting from energy consumption, persuaded the researchers to explore another source of energy. such as (wind speed energy, falling water, solar rays' energy). Solar energy is the most important source because it is availability, efficient sources, cost effective, environmentally friendly which are the advantages of the renewable energy sources. Using solar energy lead to decrease the pollution which can be done by reducing emissions to the environment. In previous studies, there are many experimental investigations have been carried out on the natural convection heat loss in the receivers with different shapes and configurations of the coils, such as: cylindrical, square, and rectangular etc. T. Taumoefolau [1], investigated experimentally the convection loss of the receiver at different inclinations. The results showed that the maximum convection loss occurs at $0^{\circ}$ and is a minimum at $90^{\circ}$. S. Paitoonsurikarn [2] studied numerically the free convection loss from cavity receivers in solar paraboloidal dishes. Three different receiver geometries have been considered. The results demonstrated a good agreement between experimental and numerical results receiver was obtained and the frustum section gave the optimum results. M. Prakash [3] carried out experimental and numerical studies. The study states that the steady state convective losses occur from downward facing cylindrical cavity receiver. The maximum deviation between the numerical and the experimental was about 14\%. Shiva Gorjian et.al [4] calculated the thermal performance of a parabolic dish collector system under different climatic and operating conditions in Tehran city-Iran during a year. The results found that the performance of the system was depending on the average temperature of the coil and the climatic or the environmental condition. Also, the result shows that the overall thermal efficiency of the system was above $40 \%$. Charles-Alexis [5] used a raytracing and a stochastic optimization method for predicting the geometry of the receivers to improve looking at radiative losses only. The results confirm that the major role of the aperture is to reduce the losses in the cavity and 
highlight the flux variation on geometries with comparable radiative performances. Yaseen and Ghaffar [6] calculated the energy, engineering characteristics of solar concentrators by writing their own equations in MATLAB program. Their results show that the comparison of the theoretical results with the other researchers was compatible. Thakkar et.al, [7], presented a performance of a parabolic dish collector PDC used for heating thermal fluid for process heating application. Barbosa1, et.al [8] studied the Parabolic Dish Collector system with tracking system design of low cost. They presented a thermal and optical modeling and performance analysis through experimental tests. The results showed that the application of tracking structure to the concentrator is important because minimum delay of the solar radiation collection lead to noticeable reduction in the system efficiency. Moreover, it was found that the external parameters can affect the optical and geometrical properties of the collector, the absorptivity and the position of the receiver as well as the climatic or environmental conditions (essentially the wind speed and clouds). PAVLOVI et.al [9] confirmed that the thermal and optical analyses for a parabolic dish collector system with a spiral absorber receiver, and designed collector with software Solid Works and simulated, thermally and optically in its Flow Simulation Studio. López et.al [10] studied the convective heat loss for a modified cavity of low-cost concentrating solar power plant. Rajendran et.al [11], investigated experimentally a focus point with dish reflector the aperture area for the dish $\left(12 \mathrm{~m}^{2}\right)$, exposed to direct normal irradiations of $810 \mathrm{~W} / \mathrm{m}^{2}$. This study focuses on increasing the exergy and energy efficiencies of the receiver by minimizing the difference between the wall temperature and heat transfer fluids temperature.

\section{2-OBJECTIVES}

The main aim of this study is development of Parabolic Dish Collector System (PDCS). PDCS can be developed by designing new shape of the absorber to reduce heat loss. Performance of PDCS will be investigated by taking into consideration different configurations and mass flow rates.

\section{3- MODEL DESCRIPTION AND EXPERIMENTAL WORK}

The schematic diagram of the experimental setup is shown in Figure (1). The system consists of dish manufactured from galvanized steel which is coated with the reflective material. Aluminum sheets was selected because of its cheap, availability and easily mounting. Parabolic dish collector has two tracking axes system for solar radiation tracking. The diameter of the dish is $1.5 \mathrm{~m}$, it has focal length and aperture area are $0.74 \mathrm{~m}$ and $3.14 \mathrm{~m}^{2}$ respectively. The receiver is located at the focus point which is working as a heater to heat up the working fluid to generate steam. The receiver consists from shell and absorber as shown in (Figure 2a). There are two types of absorbers. The first one is spiral -conical absorber which consists of two segments with three different diameters $20 \mathrm{~cm}, 8 \mathrm{~cm}, 10 \mathrm{~cm}$. The second type is spiral -helical coil which consists of two segments with two different diameters $20 \mathrm{~cm}$ and $8 \mathrm{~cm}$ as shown in fig (2b). Copper has high absorptivity of $85 \%$, high thermal conductivity of $386.3 \mathrm{~W} / \mathrm{m} \mathrm{K}$ and its melting point is over $1000^{\circ} \mathrm{C}$. The cold water is flowing in the pipes of the receiver from a water tank of 250 liter using a pump. A flow meter is used to measure the mass flow rate of the heat transfer fluid (cold water) that's entering the receiver. The K-type thermocouples were used to measure the temperatures of the fluid in the tube at inlet and outlet). The working fluid in flowing through an open loop. The outlet water from the receiver is not return back to the inlet cold water supply tank. The copper pipe is circular cross-section with of the absorber diameter is 6 $\mathrm{mm}$ for each absorber. The cavities diameters of absorbers are equal to the opining diameters approximately. The absorber is fixed by welding and bending processes. 


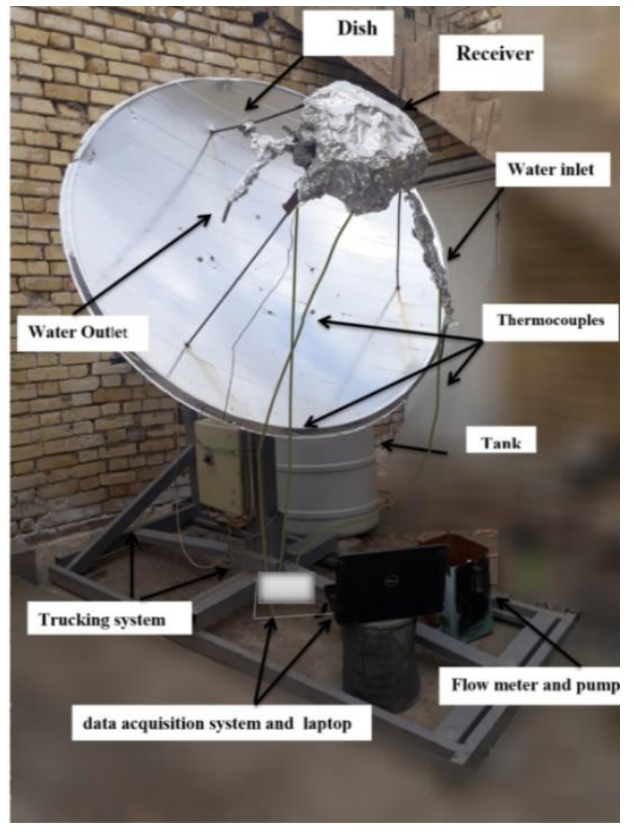

Fig.1. Parabolic Reflector of Dish Collector.

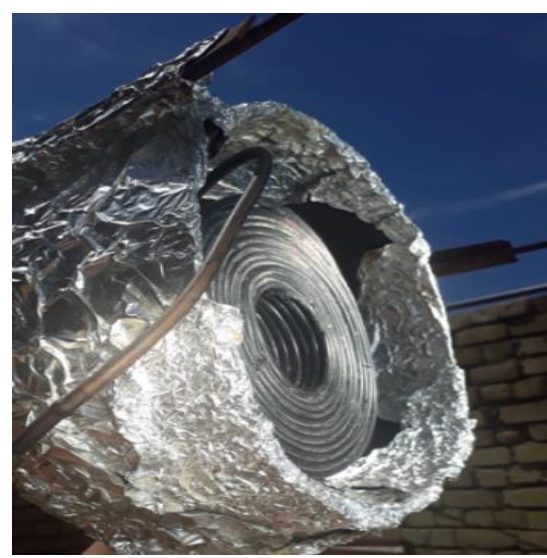

a. copper absorber

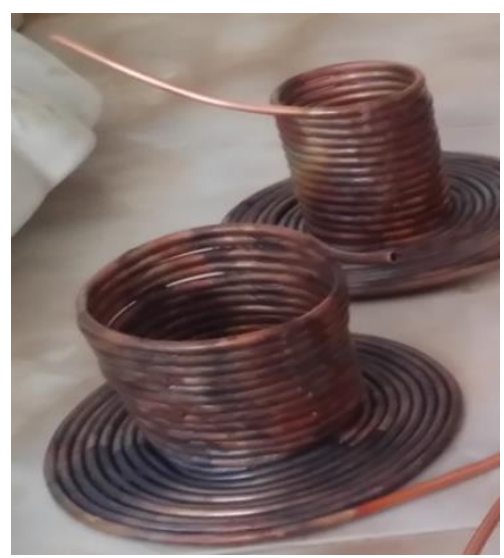

b. type of coils: A-spiral- helical coil (SHC)

Fig.2. spiral-conical coil (SCC).

\section{4- THE DESCRIPTION MODEL}

Some parameters must be defined in the study of the solar dish collector, such as

\subsection{The geometric concentration ratio $(\mathrm{CRg})$}

It is can be defined as the ratio between the collector aperture area $\left(\mathrm{A}_{\mathrm{a}}\right)$ to the surface area of the receiver $\left(\mathrm{A}_{\mathrm{r}}\right)$ and is calculated from Eq. (1)[9].

$$
\mathrm{CR}_{\mathrm{g}}=\mathrm{A}_{\mathrm{a}} / \mathrm{A}_{\mathrm{r}}
$$

\subsection{The optical concentration ratio (CRo)}

It is the ratio between the radiation that reaches the receiver $\left(I_{\text {rec }}\right)$ and the incident beam radiation on the reflective surface area $\left(\mathrm{I}_{\text {sur }}\right)$. 


$$
\mathrm{CR}_{\mathrm{o}}=\mathrm{I}_{\mathrm{rec}} / \mathrm{I}_{\text {sur }}
$$

\subsection{Optical efficiency ( $\zeta$ )}

It can be define as the performance of the collector through the quantification of the incident sun rays on the reflective surface and the reflected radiation on the receiver or is the ratio between the absorbed energy by the receiver and the incident energy on the collector's aperture. For that, some parameters need to be considered, as defined in Eq. (3):

$$
\xi_{0}=\alpha \rho \Gamma \tau \cos (\theta)
$$

where $\rho$ is dish reflectance, $\Gamma$ is the capture ratio, $\Theta$ is the angle of incidence and $(\tau \alpha)$ is transmittance-absorptance product. As the solar parabolic dish collector maintains its optical axis always focused the sun to reflect the beam, which means the incidence angle of solar beam into the dish, is zero degree. The Eq. (4) can be written as:

$$
\xi_{0}=\alpha \rho \Gamma \tau
$$

The optical efficiency depends on the optical properties of the materials used, the various imperfections arising from the construction of the collector and the geometry of the collector [6].

\subsection{The thermal efficiency}

is the ratio between the delivered (useful) energy to the working fluid to the energy incident on the dish aperture.

$$
\eta_{t h}=Q_{u} / Q_{s}
$$

\subsection{Useful heat}

The useful energy $\left(\mathrm{Q}_{\mathrm{u}}\right)$ delivered by a solar dish collector system is equal to the energy absorbed by the receiver, which is calculated by the product (solar energy falling on the receiver and optical efficiency) (optical heat, $Q_{a b c}$ ) minus the direct heat losses $\left(\mathrm{Q}_{1}\right)$ from the receiver to the surroundings [12].

$$
Q_{u}=Q_{a b c}-Q_{l}
$$

\subsection{Energy loss estimation}

The overall thermal losses from the receiver is calculated using the following equation.

$$
Q_{t o t l}=\dot{m}\left(h_{f o}-h_{f i}\right)
$$

The total heat loss is function of temperature which is mean it increases with increasing in temperature difference. The heat loss from the receiver wall is due convection and radiation modes of heat transfer to the surroundings and is given by the relation,

\subsection{The total heat loss rate of the receiver $Q_{l}$}

The total heat loss rate of the receiver $\mathrm{Q}_{\mathrm{l}}$ includes three kinds of heat: (1) convective heat loss, $\mathrm{Q}_{\mathrm{lc}}$, (2) conductive heat loss from, $\mathrm{Q}_{\mathrm{lk}}$, and (3) radiative heat loss of the coil, $\mathrm{Q}_{\mathrm{lr}}$. The total heat loss $\mathrm{Q}_{\mathrm{l}}$ can be expressed as:

$$
Q_{l}=Q_{l k}+Q_{l c}+Q_{l r}
$$


The outer wall of the receiver is covered by insulation material to reduce the conductive heat loss. Many studies have showed that the conductive loss is normally has small effect compared to the convection and radiation losses, so in this study the outer walls of the absorber are considered to be adiabatic and the conductive heat loss $\mathrm{Q}_{\mathrm{lk}}=0$. [5].

\section{1- Convection heat loss $\left(Q_{l c}\right)$}

Among the different kinds of heat loss mentioned above, the convection is the most difficult phenomenon and yet also a major contributor of the total energy loss especially about cavity receivers. The convection losses can be obtained by Eq. (9) [5].

\section{2- Radiation heat losses}

$$
Q_{l c}=h_{c v} A_{r e c}\left(T_{r e c}-T_{a m b}\right)
$$

The radiation heat loss is directly proportional to the difference in temperature to the fourth power and emittance of the surface. These losses are associated to the fourth of the temperature power of the receiver surface, or, i.e. Eq. (10). However, they can be reduced by reducing the absorber area and by increasing the receiver absorptivity. First of all, it is necessary to calculate the radiation coefficient hr through Duffie equation given by Eq. (11).

$$
\begin{aligned}
Q_{r a d} & =h_{r} A_{r}\left(T_{r e c}-T_{a m b}\right) \\
h_{r} & =4 \sigma \varepsilon_{a b s}\left(T_{a m b}\right)^{\wedge} 3
\end{aligned}
$$

where " $\varepsilon_{\mathrm{abs}}$ is the emittance of the absorber surface, $\sigma$ is the Stefan-Bolzmann constant and $\mathrm{T}_{\mathrm{amb}}$ is the ambient temperature $\mathrm{T}_{\text {rec }}$ is the temperature the absorber.

Exergy is defined as the maximum work which can be produced by a system, flow of matter or energy as it comes to equilibrium with a reference environment. The study of exergy analysis has the advantage to the designers to achieve optimum design parameters and gives direction to decrease exergy losses. The exergetic efficiency is calculated from equation [20].

The exergy output is given by the following equation:

$$
\eta_{\text {ex }}=E_{u} / E_{s}
$$

$$
E_{u}=m \cdot c p \cdot\left[\left(T_{o}-T_{i}\right)-T_{a m b} \ln \left(\frac{T_{o}}{T_{i}}\right)\right.
$$

The useful exergy from the working fluid is the useful heat diminished by the entropy generation of the process. This is the maximum possible work that can be produced, if this heat is the source of a canto cycle. The solar radiation exergy is given by equation [14] where $\mathrm{T}_{\mathrm{amb}}$ is the ambient temperature and $\mathrm{T}_{\text {sun }}$ the sun temperature:

$$
E_{s}=Q_{s} \cdot\left[1-\left[( 4 / 3 ) \cdot \left(T_{a m b} / T_{\text {sun }}+\left[(1 / 3) \cdot\left(T_{a b m} / T_{\text {sun }}\right)^{\wedge} 4\right.\right.\right.\right.
$$

TABLE 1. THE GEOMETRICAL, THE OPTICAL AND THE OPERATING DATA FOR PARABOLIC DISH SOLAR COLLECTOR

\begin{tabular}{|l|c|}
\hline \multicolumn{1}{|c|}{ Parameter } & Value \\
\hline Concentrator aperture (dish) diameter & $1.5 \mathrm{~m}$ \\
\hline Concentrator focal length $(\boldsymbol{f})$ & $0.74 \mathrm{~m}$ \\
\hline Conical receiver aperture diameters & $0.2,0.8,0.12 \mathrm{~m}$ \\
\hline Conical receiver height & $0.12 \mathrm{~m}$ \\
\hline Cylindrical receiver aperture diameters & $0.2,0.8 \mathrm{~m}$ \\
\hline optical efficiency & 0.57 \\
\hline HTF mass flow rate & $0.1,0.3,0.5 \mathrm{l} / \mathrm{min}$ \\
\hline Solar radiation & $600-950 \mathrm{~W} / \mathrm{m}^{2}$ \\
\hline The concentration ratio is & 56.25 \\
\hline
\end{tabular}




\section{5-RESULTS AND DISCUSSION}

Testing was done during sunny and cloudy days during December and November 2018. All the experiments were performed in AL KUT city-Iraq, (32.5 latitude and 45.82 longitude). The period of the test was taken between 10 am to $2 \mathrm{pm}$. Fig (2:a) shows the experimental test were conducted at $27^{\text {th }}$ of December, 2018 at clear sky day for (spiral-helical) at $0.1 \mathrm{~L} / \mathrm{min}$ mass flow rate . The solar beam varied between $\left(800 \mathrm{~W} / \mathrm{m}^{2}\right)$ and $\left(920 \mathrm{~W} / \mathrm{m}^{2}\right)$. We noticed from figure that the maximum temperatures of the absorber and water outlet $335^{\circ} \mathrm{C} 136^{\circ} \mathrm{C}$. The carve of inlet temperature and ambient temperature are same to be steady and closed. Fig (2.b) shows the experimental tests were conducted at $31^{\text {th }}$ of December, 2018 at clear sky day test was done for (spiral-conical) at $0.1 \mathrm{~L} / \mathrm{min}$ mass flow rate. Beam solar intensity varied between $800 \mathrm{~W} / \mathrm{m}^{2}$ and $950 \mathrm{~W} / \mathrm{m}^{2}$. Maximum temperatures of absorber and water outlet $(312,122)^{\circ} \mathrm{C}$.

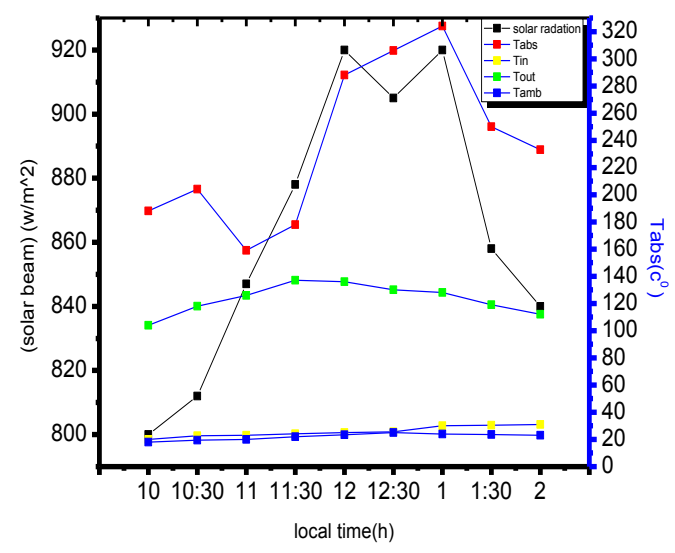

a

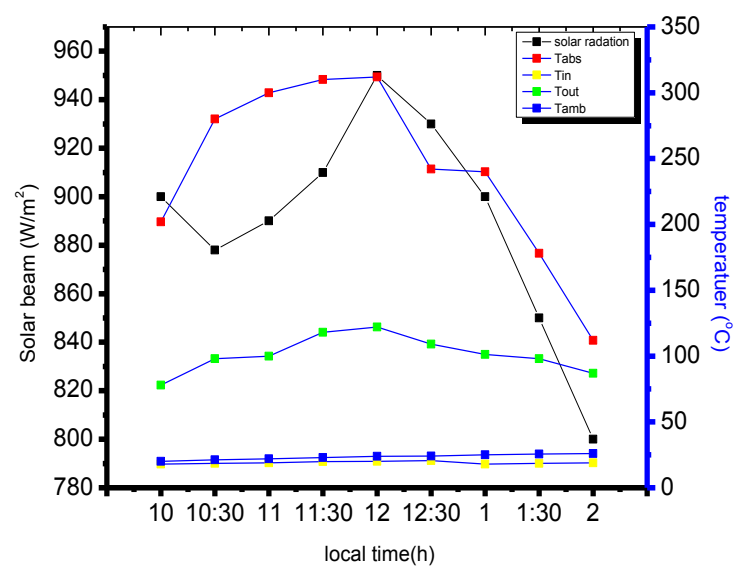

b

Fig.3. Temperatures for 0.1 1/min at (a) 27 of December and (b) 31 of December.

From the figures above we observed that the hourly solar intensity its effects on the various performance parameters of the solar parabolic concentrator. The increasing in solar beam lead to an increase in absorber temperature. The absorber temperature and outlet temperature for the (spiral helical) absorber higher than the outlet and absorber temperature of the (spiral conical) coil for the same flow rate because spiral conical absorber has higher surface area and longer than spiral helical coil. The figures $(4,5,6)$ shows the relation between the useful energy, thermal efficiency, exergy efficiency and solar radiation with the time. The useful energy, thermal efficiency and exergy efficiency are increasing functions of solar intensity which means that itis increasing with the increase in the solar intensity as shown in figures. They are varying with solar radiation variation, when the solar radiation increased it is increasing too in clear climate, except in some climate (windy, partial cloudy, most cloudy). The higher values of useful energy calculated for spiral helical absorber at $0.1 \mathrm{~L} / \mathrm{min}$ rate in clear sky because the big difference between the outlet temperature and inlet temperature. The increase in thermal efficiency for the spiral helical coil is due to the increase in useful energy because of increasing in the absorber temperature and outlet temperature at same flow rate. 


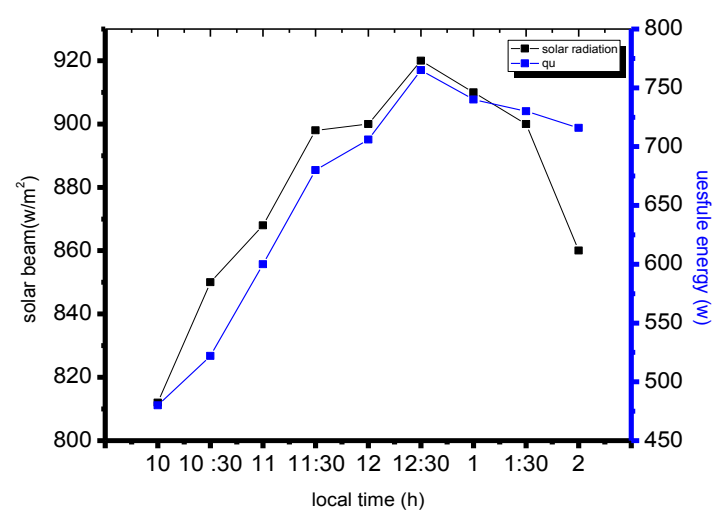

a

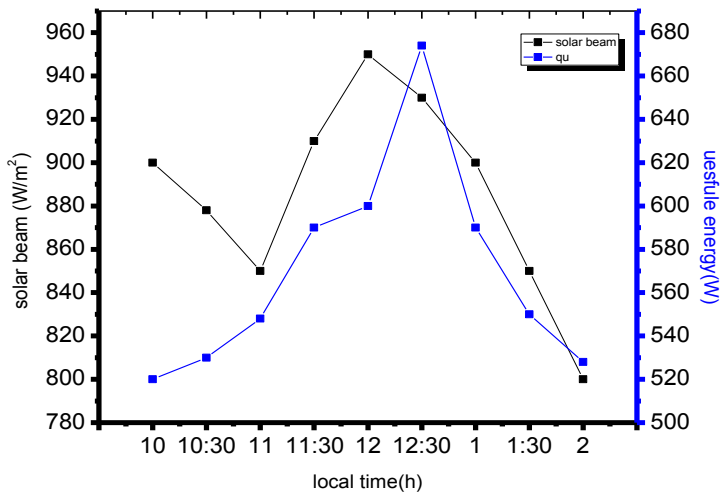

b

Fig.4. Useful energy and solar radiation for (S.H.C) at (a) 27 of December and (b) 31 of December.

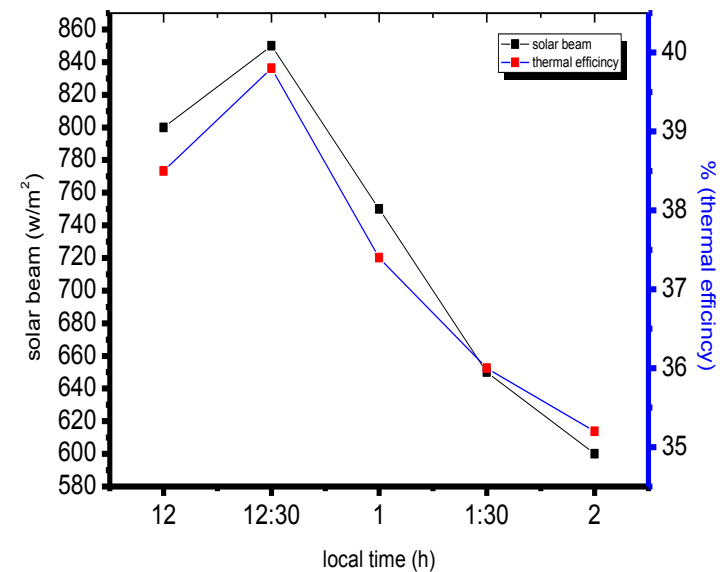

a

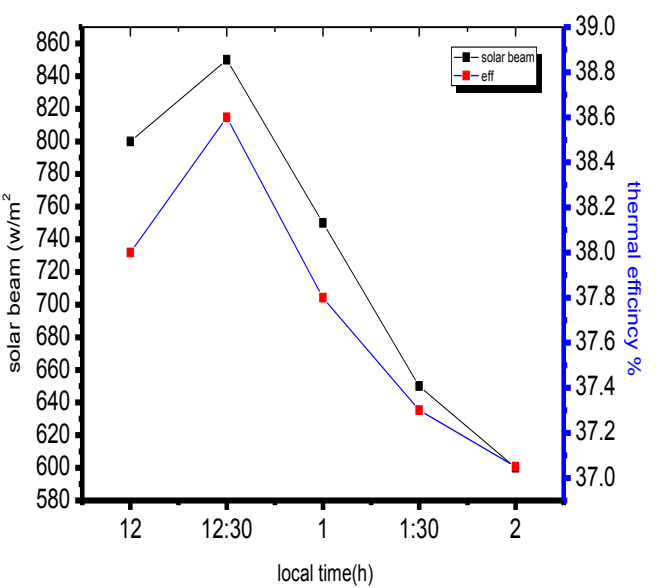

b

Fig.4. Solar radiation and thermal efficiency with time at (a) 27 of December and (b) 31 of December.

The exergtic efficiency is varying with the solar beam variation. Moreover, when the radiation is increased the efficiency will increase as shown in fig (6) In general, we noticed that the behavior of thermal efficiencies same as the behavior of useful energy when they are varying with time and this is because the efficiencies depend on the useful energy and the incident solar radiation. 


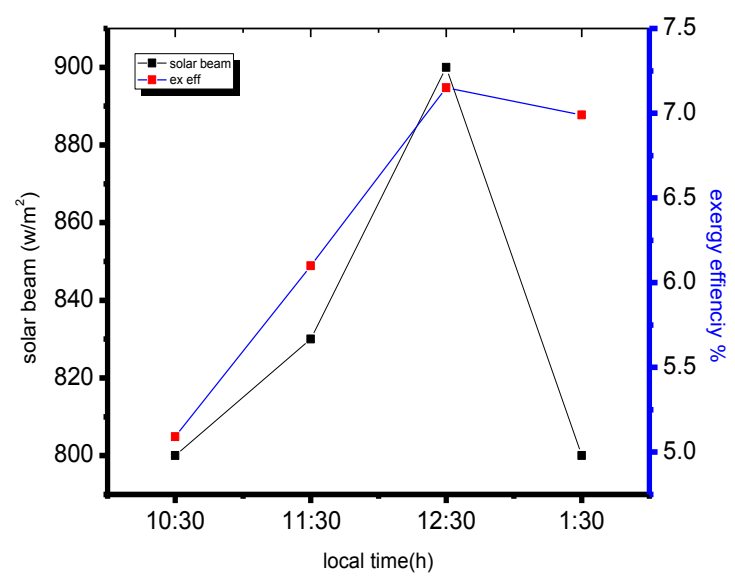

Fig.6. Solar radiation and exergy efficiency with time of all coils with $(0.1 \mathrm{~L} / \mathrm{min})$ flow rate.

Figure $(7,8)$ show the relation between solar radiation, heat convection loss and absorber temperature with time of two coils with $(0.1 \mathrm{~L} / \mathrm{min})$ flow rate, the figures show that convective heat loss increased with increasing in absorber temperature. So, the convective heat loss is an increasing function of solar intensity.

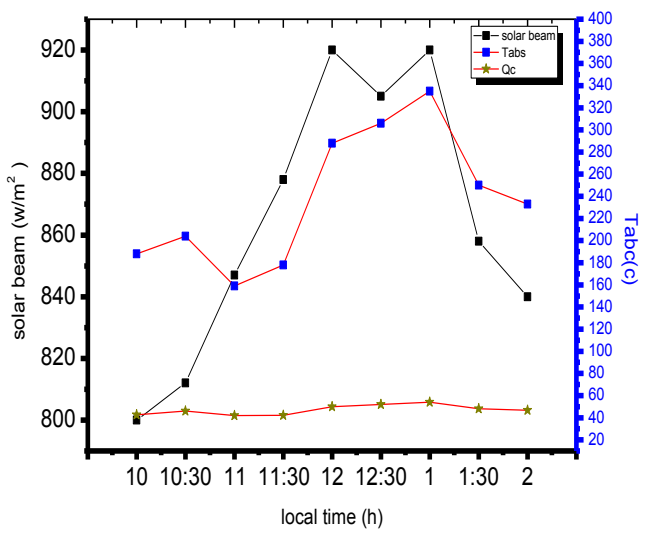

Fig.7. Solar radiation and convective heat loss with time of (S.H.C) coil at $27^{\text {th }}$ of December with $(0.1 \mathrm{~L} / \mathrm{min})$ flow rate.

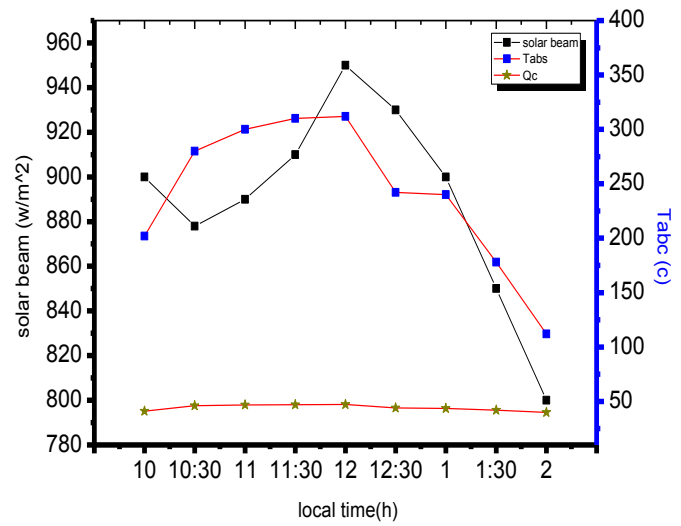


Figure (8): solar radiation and convective heat loss with time of (S.C.C) coil at $31^{\text {th }}$ of December with $(0.1 \mathrm{~L} / \mathrm{min})$ flow rate

\section{6- VALIDATION OF THE PRESENT RESEARCH}

By comparing the present work with other research such as [10]. Fig (9) shows that it same closed to this study but that the thermal efficiency of current study more than the thermal efficiency of previous study because the concentrate dish of this study higher than concentrate dish of previous study.

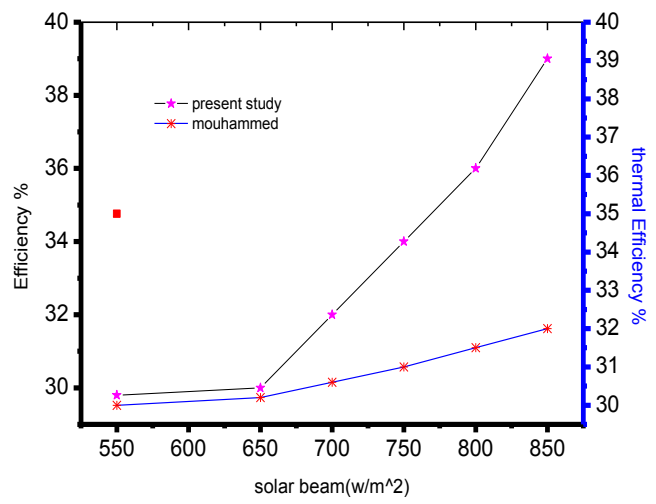

Fig.9. compares thermal efficiency with Previous Study.

Also, by comparing with other study [11] as shown in Fig (10), the carve of exergy efficiency of current study has more than exergy efficiency of previous study.

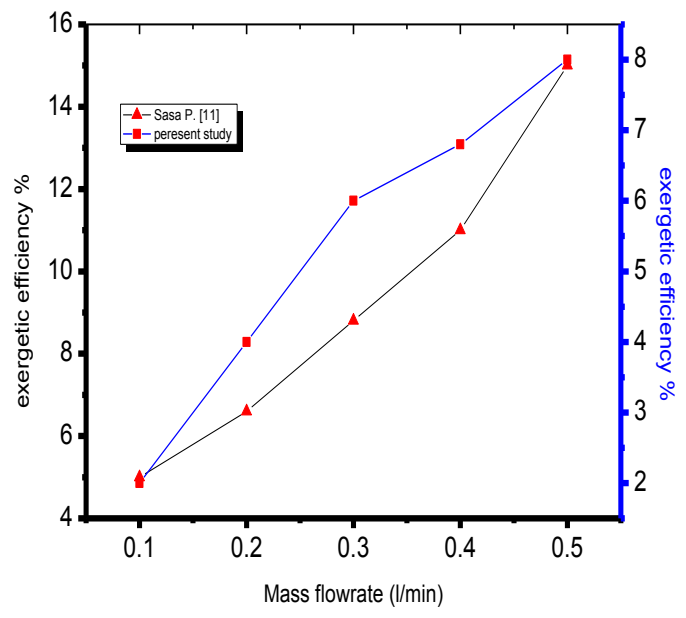

Fig.10. Compares exergy efficiency with Previous Study.

\section{7-ANALYTICAL ANALYSIS}

The numerical model was done using Microsoft Excel program. It shows the thermal performance of PDSC. The results show a good agreement with experimental results which a useful energy, thermal efficiency and exergy efficiency which is increased with increasing the solar beam in clear sky. As shown in figures (11-15). 


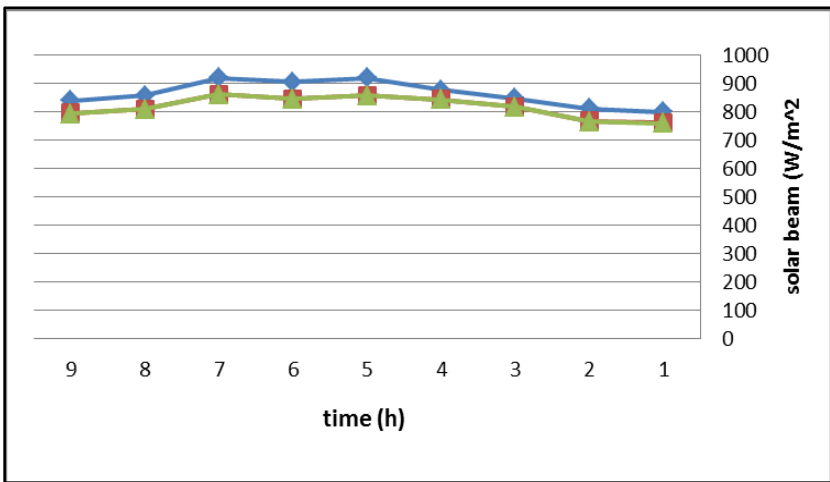

Fig.11. Useful energy and solar radiation for (S.H C) numerical and experimental analysis) at $27^{\text {th }}$ of December.

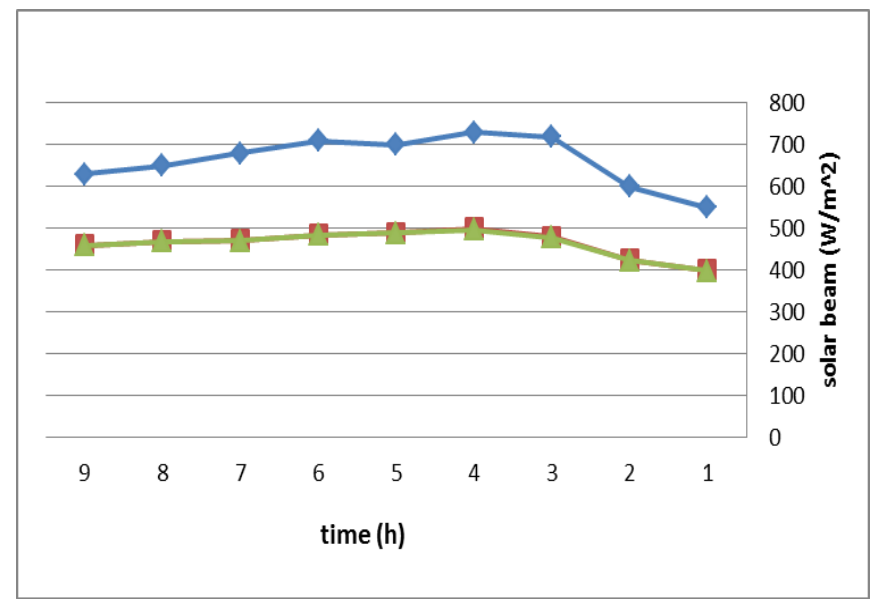

Fig.12. Relation between useful energy and solar radiation for (S.C.C) (numerical and experimental analysis) at $31^{\text {th }}$ of December.

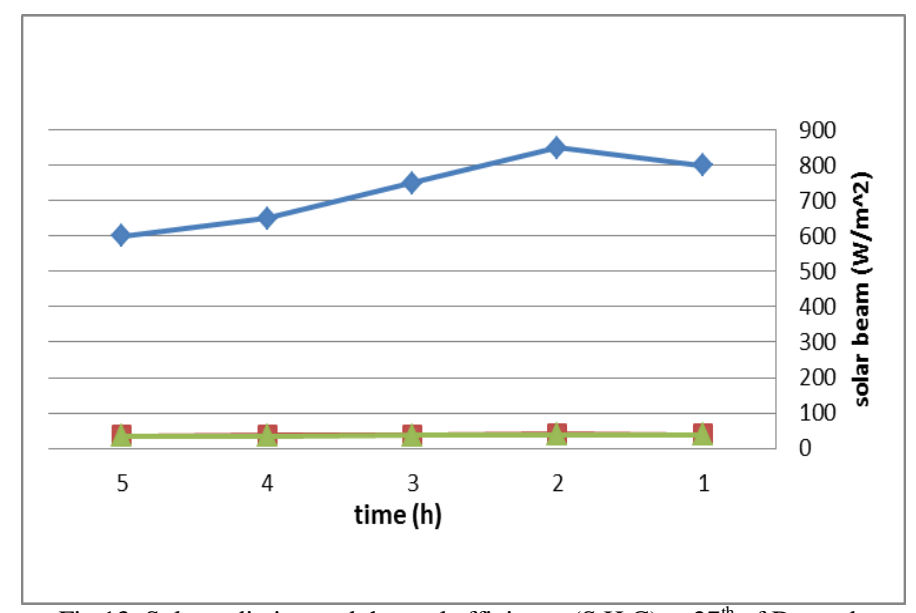

Fig.13. Solar radiation and thermal efficiency (S.H.C) at $27^{\text {th }}$ of December. 


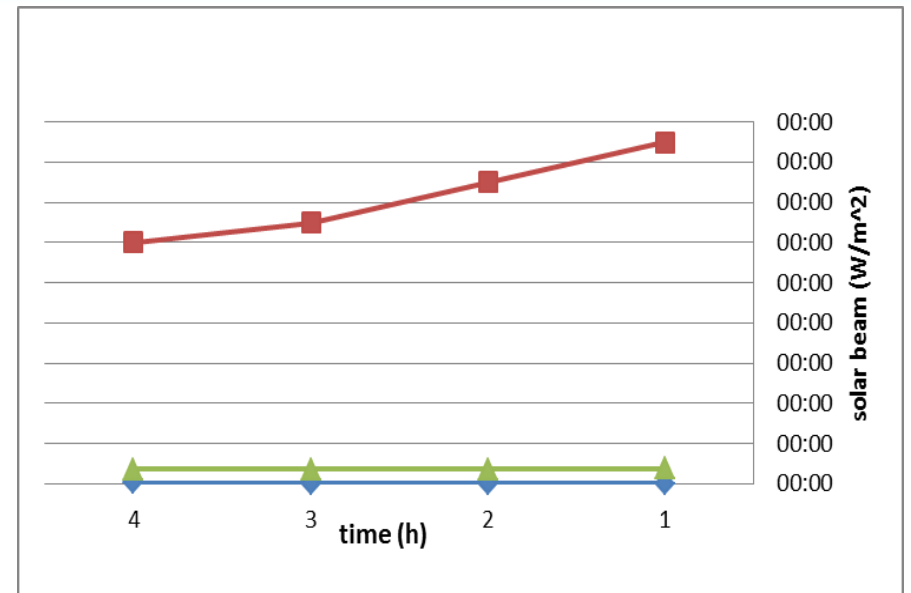

Fig.14. Solar radiation and thermal efficiency for (S.C.C) at $31^{\text {th }}$ of December.

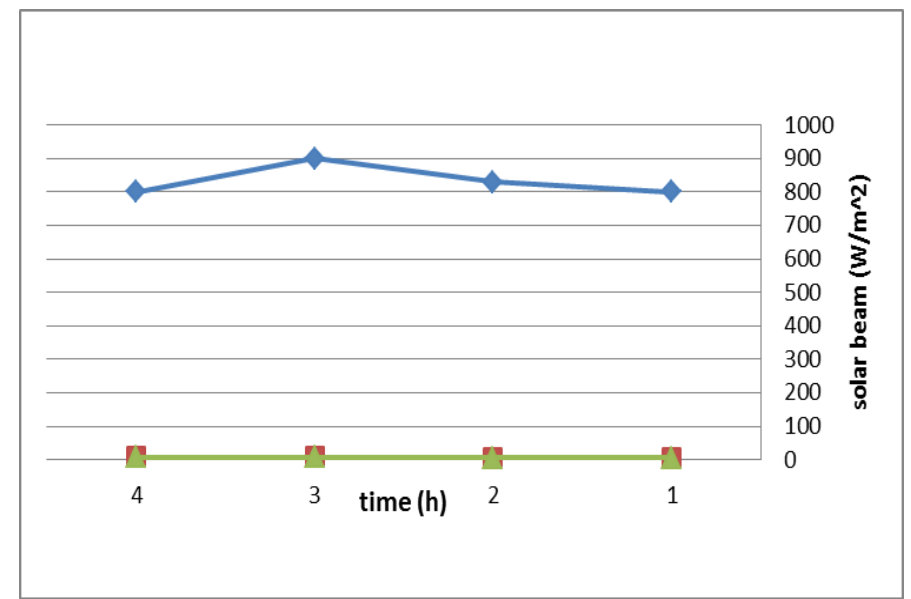

Fig.15. Solar radiation and exergy efficiency (numerical and experimental).

\section{8- CONCLUSION}

The results show that the different geometers of the absorbers effect on the performance of (PDSC) .The experimental test calculated the maximum absorber wall temperature $376 \mathrm{C}^{\circ}$ for the SHP to generated steam at lowest mass flow rate also calculate the useful energy which is varying between (480-765)w ,the thermal efficiency which is varying between(29.4-39.8)\%, and Exergy efficiency which is varying between (6.9-8.6)\%.

NOMENCLATURE

b.

TABLE 2. SAMPLES

\begin{tabular}{|l|l|}
\hline Aa & Area aperture (m2) \\
\hline Ib & Solar beam (w/m2) \\
\hline Qs & Solar energy (w) \\
\hline Qu & Useful energy (w) \\
\hline $\boldsymbol{\eta}$ th & Thermal efficiency \\
\hline Ex & Exergy efficiency \\
\hline S.H.C (A) & Spiral-helical coil \\
\hline S.C.C (B) & Spiral-conical coi \\
\hline hcv & Heat transfer coefficient \\
\hline hr & Radiation coefficient \\
\hline hfo & Enthalpy of outlet water \\
\hline hfi & Enthalpy of inlet water \\
\hline
\end{tabular}




\section{REFERENCES}

1. T. Taumoefolau , K. Lovegrove ," An Experimental Study of Natural Convection Heat Loss from a Solar Concentrator Cavity Receiver at Varying Orientation. ", Australian National University,, Canberra ACT 0200 AUSTRALIA.2002

2. S. PAITOONSURIKARN and K. LOVEGROVE," On the Study of Convection Loss from Open Cavity Receivers in Solar Paraboloidal Dish Applications ", Australian National University Canberra ACT 0200, AUSTRALIA, pp 154,155,2003

3. Soteris A. Kalogirou*,"Solar thermal collectors and applications", Higher Technical Institute, Progress in Energy and Combustion Science 30 (2004) 231-295, pp237, 240, 241, 2004

4. M. Prakash, S.B. Kedare, J.K. Nayak," Investigations on heat losses from a solar cavity receiver", Department of Energy Science and Engineering, Indian Institute of Technology Bombay, Mumbai 400076, India,2008.

5. Shiva Gorjian1, Barat Ghobadian1, Teymour Tavakkoli Hashjin1, and Ahmad Banak, "Thermal performance of a Point-focus Solar Steam Generating System ", 21st Annual International Conference on Mechanical Engineering-ISME201 7-9 May, 2013, School of Mechanical Eng., K.N.Toosi University, Tehran, Iran ,1ISME2013-1195,2013

6. Kailash Karunakaran1 Hyacinth J Kennady2,"Thermal Analysis of Parabolic Dish Snow Melting Device " ,International Journal for Research in Technological Studies| Vol. 1, Issue 3, February 2014 | ISSN (online): 2348-1439,2014

7. Charles-Alexis Asselineau, Ehsan Abbasi, John Pye "Open cavity receiver geometry influence on radiative losses" Australian National University (ANU), Canberra, ACT 0200 Australia. Solar2014: The 52nd Annual Conference of the Australian Solar Council 2014

8. Vahid Madadi, Touraj Tavakoli and Amir Rahimi First and second thermodynamic law analyses applied to a solar dish collector" DOI 10.1515/jnet-2014-0023 | J. Non-Equilib. Thermodyn. 2014; 39 (4):183-197

9. Yaseen. H. Mahmood, Mayadah K h. Ghaffar " Design of Solar dish concentration by using MATLAB program and Calculation of geometrical concentration parameters and heat transfer" , University of Tikrit , Tikrit , Iraq, Tikrit Journal of Pure Science 20 (4) ISSN: 1813 - 1662, 2015.

10. Vanita Thakkar, Ankush Doshi, Akshaykumar Rana "Performance Analysis Methodology for Parabolic Dish Solar Concentrators for Process Heating Using Thermic Fluid IOSR", Journal of Mechanical and Civil Engineering (IOSR-JMCE) eISSN: 2278-1684,p-ISSN: 2320-334X, Volume 12, Issue 1 Ver. II (Jan- Feb. 2015), PP 101-114

11. Saša R. pavlovi, Evangelos A. bellos, Velimir P. Stefanovi, Christos Tzivanidis and Zoran M. Stamenkovi "Design, Simulation , and Optimiztion Of A Solar Dish Collector with spiral coil absorber ", , Nis, Serbia, thermal SCIENCE, Vol. 20, No. 4, pp. 1387-1397 1387,2016

12. Flávia V. Barbosa, João L. Afonso, Filipe B. Rodrigues, and José C. F. Teixeir," Development of a solar concentrator with tracking system", University of Minho,Guimarães, 4800-058, Portugal2016

13. O. López, A. Arenas, and A. Baños"Convective Heat Loss Analysis of a Cavity Receiver for a Solar Concentrator" International Conference on Renewable Energies and Power Quality (ICREPQ'17)Malaga (Spain), 4th to 6th April, 2017 ,ISSN 2172-038 X, No.15 April 2017 RE\&PQJ, Vol.1, No.15, April 2017

14. D.R.Rajendran,E.GanapathySundaram,P.Jawahar "Experimental Studies on the Thermal Performance of a Parabolic Dish Solar Receiver with the Heat Transfer Fluids Sic water Nano Fluid and Water", Journal of $\begin{array}{llllll}\text { Thermal Science } & \text { Vol.26, } & \text { No.3 } & \text { (2017) } & 263 \square 272 & \text {,2017 }\end{array}$

15. Muhammad Shoaib, Muhammad, Jameel Kabbir Ali ,Muhammad Usman1, Abdul Hannan " Analysis of thermal performance of parabolic dish collectors having different reflective" ,NFC institute of engineering \&fertilizer research ,2018 .

16. Sasa PAVLOVIC, Evangelos BELLOS, Velimir STEFANOVIC ,Christos TZIVANIDIS " EXPERIMENTAL AND NUMERICAL INVESTIGATION OF A SOLAR DISH COLLECTOR WITH SPIRAL ABSORBER" A CTA TECHNICA CORVINIENSIS - Bulletin of Engineering Tome XI [2018] . 
17. Vahid Madadi, Touraj Tavakoli and Amir Rahimi," First and second thermodynamic law analyses applied to a solar dish collector" DOI 10.1515/jnet-2014-0023 | J. Non-Equilib. Thermodyn. 2014; 39 (4):183-197

18. Atul Sagade ,Nilkanth Shinde "Performance evaluation of parabolic dish type solar collector for industrial heating application"Int. J. Energy Technology and Policy, Vol. 8, No. 1, 2012

19. S.K. Tyagi, Shengwei Wang, M.K. Singhal, S.C. Kaushik ,S.R.Park "Exergy analysis and parametric study of concentrating type solar collectors" International Journal of Thermal Sciences 46 (2007) 1304-1310

20. Lloyd C. Ngo," Exergetic Analysis and Optimization of a Parabolic Dish Collector for Low Power Application" ,University of Pretoria , November 2012, https://www.researchgate.net/publication/304775136 